\title{
Fabrication of Mullite Body Using Superplastic Transient Phase
}

\author{
Liang A. Xue* and I-Wei Chen* \\ Department of Materials Science and Engineering, The University of Michigan, \\ Ann Arbor, Michigan 48109-2136
}

\begin{abstract}
Mullite, an extremely creep-resistant ceramic, has been fabricated using a novel processing/forming approach taking advantage of superplastic transitional phases. Starting with a mixture of alumina, silica, and a small amount of lithia additive $(0.8 \mathrm{wt} \%)$, a processing window of about $50^{\circ} \mathrm{C}$ around $1350^{\circ} \mathrm{C}$ has been found within which the material can be densified and superplastically deformed with negligible mullitization. The lithia additive promotes a transient lithium aluminosilicate glassy phase that greatly enhances sintering and deformation. The superplastic premullite maintains a nearly constant grain size during deformation between $1250^{\circ}$ and $1400^{\circ} \mathrm{C}$, over a strain rate from $6 \times 10^{-7}$ to $10^{-1} \mathrm{~s}^{-1}$, and has unusually high activation energy values in the range of 1150 to $2086 \mathrm{~kJ} / \mathrm{mol}$. An increase in the transient glassy phase content due to the increased matrix dissolution at higher temperatures contributes in part to this anomaly. The mullite work pieces thus shaped become creep resistant again after a postforming annealing/mullitization treatment which decreases the creep rate by 6 orders of magnitude. The mechanical properties (hardness, toughness, and strength) of the finished mullite are compared to those of conventionally processed mullite. [Key words: mullite, superplastic, sintering, microstructure, mechanical properties.]
\end{abstract}

\section{Introduction}

Quperplastic ceramics are usually developed by refining $\$$ the grain size to a scale of around $0.25 \mu \mathrm{m} .{ }^{1}$ Examples of these types of ceramics are TZP ${ }^{2}$ alumina, ${ }^{3}$ hydroxyapatite, ${ }^{4}$ $\mathrm{Si}_{3} \mathrm{~N}_{4},{ }^{1} \mathrm{Si}_{3} \mathrm{~N}_{4} / \mathrm{SiC},{ }^{5}$ spodumene glass-ceramics, ${ }^{6}$ and several TZP composites with alumina and mullite. ${ }^{1,7}$ Superplastic forming of some of the above ceramics has been attempted. ${ }^{1,3}$ In the more favorable cases, a forming stress less than $50 \mathrm{MPa}$ and a forming rate greater than $10^{-4} \mathrm{~s}^{-1}$ can be achieved. These conditions might be considered to define a forming window for potential applications of superplasticity for net shape forming. Mullite, on the other hand, is known as an extremely creep-resistant ceramic. ${ }^{8-14}$ This can be appreciated by reviewing the data of fine-grained mullite compiled in Fig. 1. Even with a very fine grain size, e.g., $0.61 \mu \mathrm{m}$, the deformation is still much too slow compared to the desirable superplastic forming window. Indeed, taking the experimentally determined value of the grain size exponent of 1.2 to $2.5,{ }^{14}$ we estimate a grain size much smaller than $0.1 \mu \mathrm{m}$ to be required to achieve deformation rates comparable to those obtained for other superplastic ceramics. Such a fine-grained microstructure would be very difficult to produce by conventional processing; moreover, it probably would be unstable be-

M. D. Sacks - cont ributing editor

Manuscript No. 196412. Received August 29, 1991; approved January 9 , 1992.

Supported by the National Science Foundation under Grant No. DDMSupporter
9024975.

*Member, American Ceramic Society. cause of dynamic grain growth ${ }^{3}$ In the present work, we report a novel processing approach to overcome these obstacles.

The approach we used enabled us to obtain a deformable "premullite" which contains two constituent compounds, alumina and silica, both having a lower creep resistance than that of mullite itself. With the further help of a small amount lithia additive, which forms transient glassy phases with alumina and silica, dramatically enhanced formability was achieved. The mixture was first sintered to obtain a dense alumina/silica body which can readily be superplastically shape formed. The shaped work piece was then converted to mullite by postforming annealing. In the following, this transient phase-forming process, the deformation characteristics of the premulite, and the mechanical properties of the finished mullite are described.

\section{Experimental Procedure}

The starting materials were a high-purity alumina powder with an average particle size of $\sim 0.2 \mu \mathrm{m}$ (AKP-50, Sumitomo Chemical America, Inc., New York) and a high-purity amorphous silica with an average particle size of $\sim 0.04 \mu \mathrm{m}$ (Aerosil OX50, Degussa Corp., Ridgefield Park, NJ). Silica powder was first dispersed in distilled water under ultrasonic agitation with the acid of a surfactant (Darvan 821A, R.T. Vanderbilt Co. Inc., Norwalk, CT). To the dispersed suspension, an aqueous solution of lithium nitrate was added. The amount of additive introduced was such as to obtain $0.8 \mathrm{wt} \%$ of lithia in the final, stoichiometric mullite composition (72 wt\% alumina with 28 wt\% silica). The slurry was subsequently dried and calcined at a temperature of $1050^{\circ} \mathrm{C}$ for $30 \mathrm{~min}$. The doped silica powder was dispersed again and mixed with alumina powder by attrition milling. The latter slurry was cast, under a pressure of $1 \mathrm{MPa}$, into cakes of 47 $\mathrm{mm}$ diameter, which were dried first in a moisture-controlled environment, then in air, and finally in an oven at tempera-

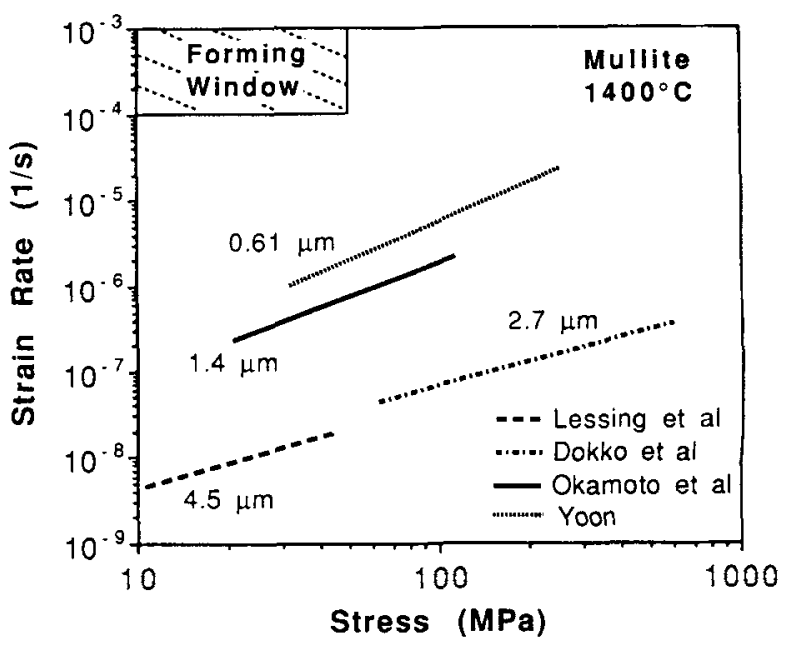

Fig. 1. Relationship between strain rate and stress for mullite of various grain sizes. Data of Lessing, Dokko, Okamoto, and Yoon are from Refs. $8,9,11$, and 12 , respectively. 
tures up to $150^{\circ} \mathrm{C}$. After isostatic pressing, these cakes were sintered in air at temperatures ranging from $1250^{\circ}$ to $1600^{\circ} \mathrm{C}$ for $2 \mathrm{~h}$. Some sintered samples were further subjected to an annealing treatment at $1650^{\circ} \mathrm{C}$ for $8 \mathrm{~h}$ to obtain mullitized specimens.

$\mathrm{X}$-ray diffraction (XRD), using Ni-filtered $\mathrm{Cu} K \alpha$ radiation, and differential thermal analysis (DTA) were employed to follow the reactions and phase evolution. The microstructures of the sintered and/or annealed samples were characterized by scanning electron microscopy (SEM) and transmission electron microscopy (TEM). Because of the presence of various transient phases, the relative density was estimated from porosity measurements using the standard metallographic lineal analysis. A minimum test line length of $195 \mu \mathrm{m}$ over a test area of at least $31 \mu \mathrm{m}^{2}$ on SEM micrographs of polished specimens was used for such measurements. The same technique was also employed in the estimation of the glassy phase content.

Samples sintered at $1320^{\circ} \mathrm{C}$ which reached a relative density of $99 \%$ were used for mechanical testing. Specimens for the compression test in the form of square bars were cut from these disks. Uniaxial compression was conducted between $1250^{\circ}$ and $1400^{\circ} \mathrm{C}$ with strain rates from $6 \times 10^{-7}$ to $10^{-1} / \mathrm{s}$. Specimens for the superplastic punch-stretching test were obtained by grinding these disks on two surfaces to a thickness of $1.2 \mathrm{~mm}$. The experimental details for superplastic stretching were similar to those reported elsewhere. . $^{3.15}$

For the mullitized specimens, the Vickers indentation technique was employed to measure the hardness and the fracture toughness. ${ }^{16}$ A load of $20 \mathrm{~N}$ was used. Flexural strength measurements were performed in four-point bending with an $8-\mathrm{mm}$ inner span and a $16-\mathrm{mm}$ outer span on specimens with dimensions of $2.2 \mathrm{~mm} \times 3.1 \mathrm{~mm} \times 25.0 \mathrm{~mm}$. Both room-temperature and high-temperature (up to $1400^{\circ} \mathrm{C}$ ) fracture strength were measured.

\section{Results and Discussion}

\section{(1) Transient Phase Processing}

The separate calcination step for silica was introduced primarily to incorporate lithia, which would otherwise be lost to water during pressure slip casting. XRD shows that after calcination, the initially amorphous silica powder has crystallized to a mixture of quartz and cristobalite (tridymite has also been found in some cases), and the lithia has formed, with silica, a composition close to $\mathrm{Li}_{2} \mathrm{Si}_{2} \mathrm{O}_{5}$. During sintering, the latter further reacts with alumina to form transient glassy boundary phases which, during cooling, seem to crystallize to compositions such as $\mathrm{Li}_{0.6} \mathrm{Al}_{0.6} \mathrm{Si}_{2.4} \mathrm{O}_{6}$. This is illustrated in Fig. 2, which shows XRD patterns for samples sintered at various temperatures for $30 \mathrm{~min}$. Before sintering, the green body contains cristobalite (C), quartz (Q), $\alpha$-alumina (A), and a small amount of lithium silicate $\left(\mathrm{Li}_{2} \mathrm{Si}_{2} \mathrm{O}_{5}\right)(\mathrm{L})$. It can be seen that the lithium silicate phase dissolves first during heating. Above $900^{\circ} \mathrm{C}$, the amount of quartz gradually decreases and entirely disappears by $\sim 1250^{\circ} \mathrm{C}$. Comparing the relative peak height of alumina and silica phases, it is also evident that at temperatures $>1000^{\circ} \mathrm{C}$, reactions between alumina, cristobalite, quartz, and the lithium silicate occur which consume the latter phases. This accelerates with the increase in temperature, most likely resulting in a transient lithium aluminosilicate melt which presumably crystallizes to some extent during cooling to a phase (G in Fig. 2) with a composition such as $\mathrm{Li}_{0.6} \mathrm{Al}_{0.6} \mathrm{Si}_{2.4} \mathrm{O}_{6}$ and $\mathrm{LiAlSi}_{3} \mathrm{O}_{8}{ }^{17,18}$ (Note that the consumption of $\mathrm{Al}_{2} \mathrm{O}_{3}$ is much less than that of $\mathrm{SiO}_{2}$ for these compositions.) The observation is in agreement with the DTA experiment which detects an endothermic peak that begins at $1269^{\circ} \mathrm{C}$ and reaches its maximum at $1300^{\circ} \mathrm{C}$, suggesting the formation of a glassy melt in this temperature range. This transient glassy phase greatly facilitates the sintering and deformation process, as will be discussed later. With the further rise in the temperature, mullitization occurs. At $1400^{\circ} \mathrm{C}$ a no-

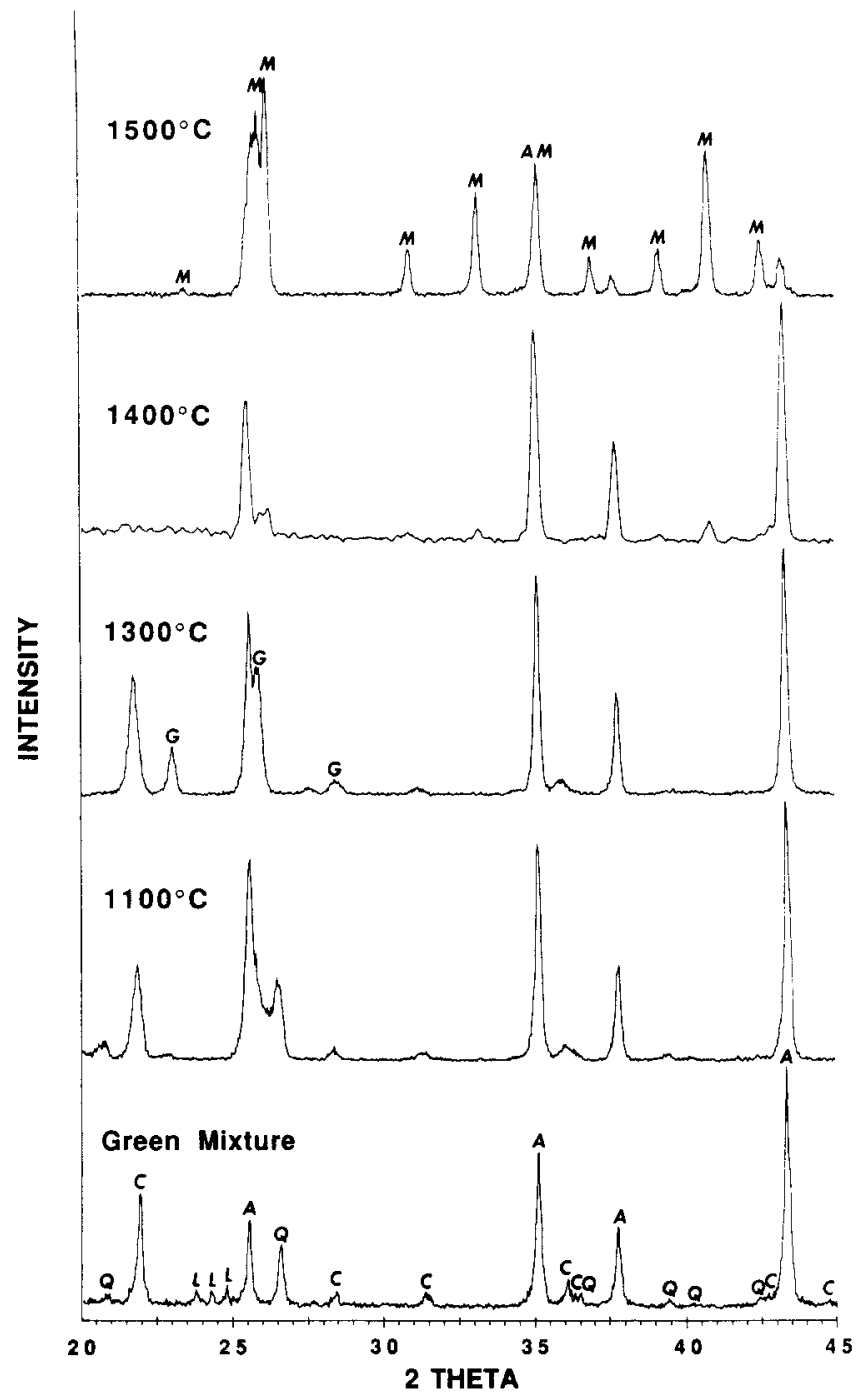

Fig. 2. XRD patterns of lithia-doped silica/alumina mixture calcined at various temperatures for $30 \mathrm{~min} . A=$ alumina $\mathrm{C}=$ cristobalite, $\mathrm{Q}=$ quart $\mathrm{z}, \mathrm{L}=$ lithia silicate, with a composition close to $\mathrm{Li}_{2} \mathrm{Si}_{2} \mathrm{O}_{5} ; \mathrm{G}=$ lithium aluminosilicate glass which, during cooling, crystallizes to $\mathrm{Li}_{0.6} \mathrm{Al}_{0.6} \mathrm{Si}_{2.4} \mathrm{O}_{6}$ and $\mathrm{LiAlSi}{ }_{3} \mathrm{O}_{8}$; and $\mathrm{M}=$ mullite.

ticeable amount of mullite $(\mathrm{M})$ is already observed but the majority of it forms by $1500^{\circ} \mathrm{C}$. Lithia apparently promotes the mullitization; for example, an undoped silica/alumina mixture experiences no mullitization until above $1450^{\circ} \mathrm{C}$.

The processing condition we sought was one that allowed sintering to nearly full density without incurring significant mullitization so deformation could then be conducted at such a temperature (or slightly higher) by viscous flow. To define the processing window more accurately, sintering and mullitization kinetics of the $\mathrm{Al}_{2} \mathrm{O}_{3} / \mathrm{SiO}_{2}\left(\mathrm{Li}_{2} \mathrm{O}\right)$ compact were first determined. The results are shown in Fig. 3, where we plot both the relative density and the mullite fraction as a function of sintering temperature. Here, the sintering time used was $2 \mathrm{~h}$, and the mullite fraction expressed was obtained by using the peak intensities of mullite (121) line, $M$, and alumina (113) line, $\mathrm{A}$, and letting mullite percent $=\mathrm{M} /(\mathrm{M}+\mathrm{A})$. (AIthough this quantity does not accurately represent the actual mullite content, because of the presence of glassy phase and, to a less significant extent, the various lithium/silica/alumina phases mentioned above, it was convenient for our purpose of locating the temperature range at which substantial mullitization would occur.) Indeed, the data in Fig. 3 show that there is a $\sim 50^{\circ} \mathrm{C}$ processing window within which the dense premullite can be further processed, say by superplastic forming, 


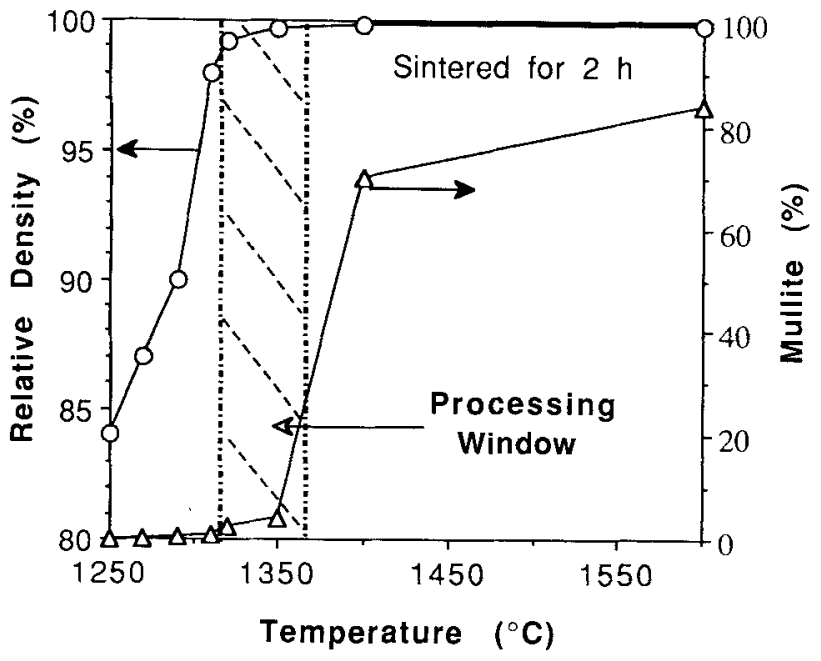

Fig. 3. Relative density of the sintered premullite and the percentage of the mullite formation as a function of sintering temperature, showing a processing window of $-50^{\circ} \mathrm{C}$.

without the adverse effect of mullitization. Accordingly, a sintering temperature of $1320^{\circ} \mathrm{C}$ was chosen to prepare all the specimens for superplastic forming and mechanical deformation studies.

The microstructure of the premullite sintered at $1320^{\circ} \mathrm{C}$ is shown in Fig. 4. The SEM micrograph (Fig. 4(a)) features a very fine-grained microstructure $(0.2$ to $0.3 \mu \mathrm{m})$ where alumina grains are surrounded by a glassy phase which appears as a darker, diffuse grain-boundary layer. The darker appearance is due to the light element lithium in the glassy phase. Some glassy pockets were also observed. A typical TEM micrograph highlighting the glassy pockets is shown in Fig. 4(b). The glassy nature of the pockets has been identified by electron diffraction. Clearly, the grain-boundary phase is multiply connected in three dimensions. Such a microstructure is consistent with the phase analysis for XRD which shows alumina and a small amount of crystallized silicate phase formed presumably during cooling of the glassy melt.

It should be mentioned that a dense silica/alumina body with the mullite stoichiometry can be achieved with or without lithia additives. Using undoped as-received silica powder, this requires $1340^{\circ} \mathrm{C}$ for $2 \mathrm{~h}$. Sacks et al. have also reported the successful sintering of such a silica/alumina mixture at even lower temperatures $\left(\leq 1300^{\circ} \mathrm{C}\right)$ using a silica-coated alumina mixture. ${ }^{19}$ Lithia doping has the same effect. However, our experience indicated that the undoped silica/alumina body could not be superplastically deformed, because of the very high flow stress in this material $\left(135 \mathrm{MPa}\right.$ at $\dot{\varepsilon}_{\mathrm{i}}=5 \times$ $10^{-5} \mathrm{~s}^{-1}$, even at $1450^{\circ} \mathrm{C}$. In the next section, we will demonstrate that a lithia additive lowers the flow stress of the glassy phase significantly. Lithia doping at less than $0.5 \mathrm{wt} \%$ was found inadequate for the forming purpose.

\section{(2) Deformation Characteristics}

Examples of typical flow stress versus true strain curves in compression at $1325^{\circ} \mathrm{C}$ for three different strain rates are shown in Fig. 5. The deformed samples contained $0.8 \mathrm{wt} \%$ lithia and were sintered at $1320^{\circ} \mathrm{C}$ for $2 \mathrm{~h}$. Low flow stresses were maintained even at relatively high strain rates, while strain hardening was negligible. Figure 6 gives two SEM micrographs of the premullite after deformation. In Fig. 6(a), the microstructure is of a sample deformed at $1325^{\circ} \mathrm{C}$, at a strain rate of $6 \times 10^{-4} / \mathrm{s}$, to a true strain of 0.2 ; in Fig. 6(b), at $1400^{\circ} \mathrm{C}, 2 \times 10^{-2} / \mathrm{s}$, and to a strain of 0.9 . No cavitation can be observed in either case, but at $1400^{\circ} \mathrm{C}$ some mullitization has already occurred, as illustrated by the two mullite crystallites labeled in Fig. 6(b). The grains have apparently remained equiaxed without grain growth, although the amount of glassy boundary phase seems to have increased somewhat. These

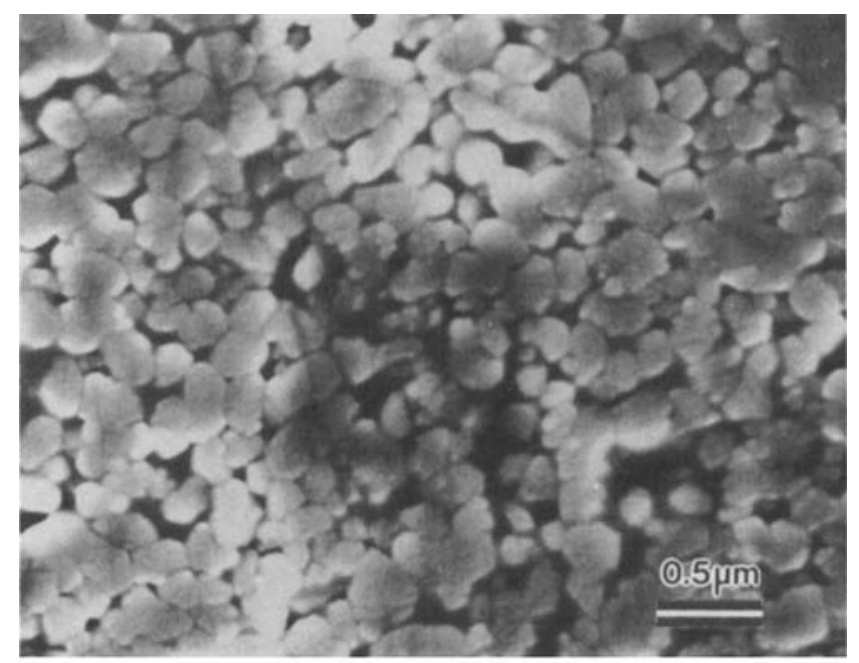

(a)

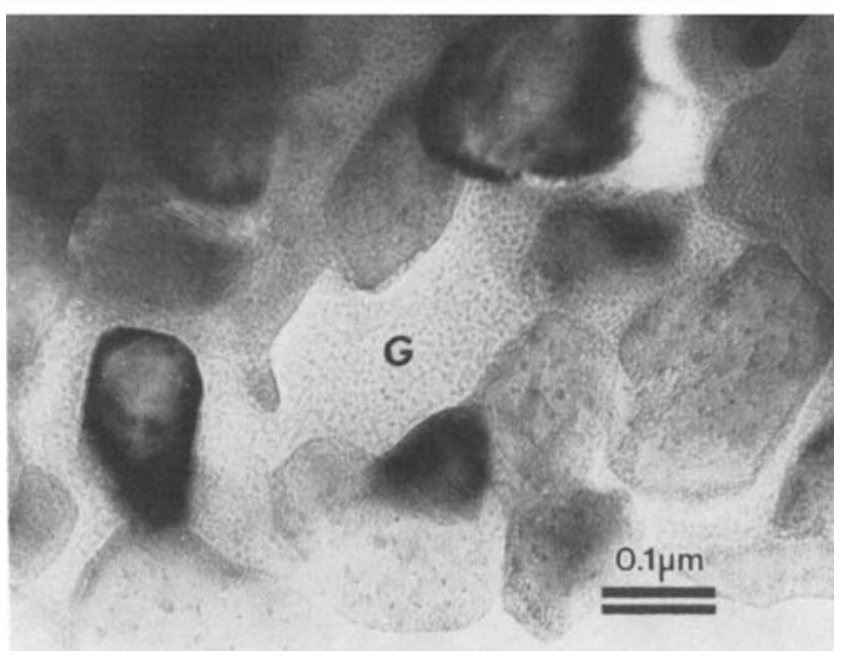

(b)

Fig. 4. (a) SEM micrograph of premullite sintered at $1320^{\circ} \mathrm{C}$ for $2 \mathrm{~h}$; (b) TEM bright-field image of the same sample, highlighting a glassy phase pocket.

features are consistent with the very low flow stress and the absence of strain hardening which usually arises from dynamic grain growth. Overall, the relative stability of the microstructure and the apparent cavitation resistance at such a low flow stress make the material an excellent candidate for superplastic forming.

The data of strain rate and flow stress at various temperatures are plotted on a logarithmic scale in Fig. 7. It can be noted that the deformation of the premullite is strongly temperature dependent. Within the experimental temperature span of $150^{\circ} \mathrm{C}$ (from $1250^{\circ}$ to $1400^{\circ} \mathrm{C}$ ), the deformation ratc increases by more than 5 orders of magnitude. There is also a shift in the slopes towards higher values with higher temperatures in a relatively sharp transition (for an $n$ value increasing from $\sim 1.7$ at the $1250^{\circ}$ to $1300^{\circ} \mathrm{C}$ range to $\sim 2.1$ at the $1350^{\circ}$ to $1400^{\circ} \mathrm{C}$ range). A similar rise in $n$ within a narrow temperature span was previously observed in a CuO-added Y-TZP superplastic ceramic and has been attributed to the melting of a grain-boundary phase and a change of deformation mechanism. ${ }^{20}$ In our case, XRD analysis of deformed specimens revealed little mullitization at large deformation $(\varepsilon=-0.7)$ and lower temperatures; however, at $1400^{\circ} \mathrm{C}$ some mullitization in the range of several percent was detected after the compression test. This was consistent with the microstructural obser- 


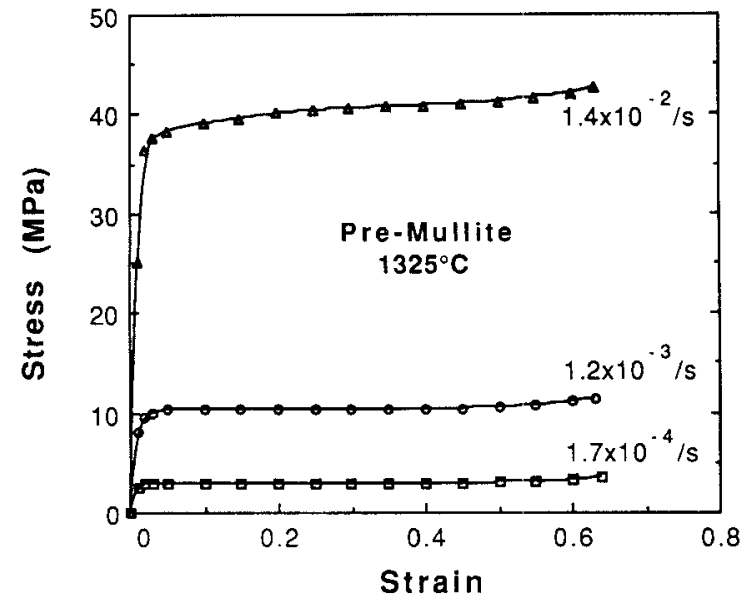

Fig. 5. Stress-strain curves for premullite deformed at $1325^{\circ} \mathrm{C}$.

vation seen in Fig. 6. The apparent activation energy for deformation is evaluated in Fig. 8 at a constant stress of $10 \mathrm{MPa}$. It decreases from $2086 \mathrm{~kJ} / \mathrm{mol}$ (for the temperature range of $1250^{\circ}$ to $1325^{\circ} \mathrm{C}$ ) to $1150 \mathrm{~kJ} / \mathrm{mol}$ (for the temperature range of $1325^{\circ}$ to $1400^{\circ} \mathrm{C}$ ). This transition in activation energy,

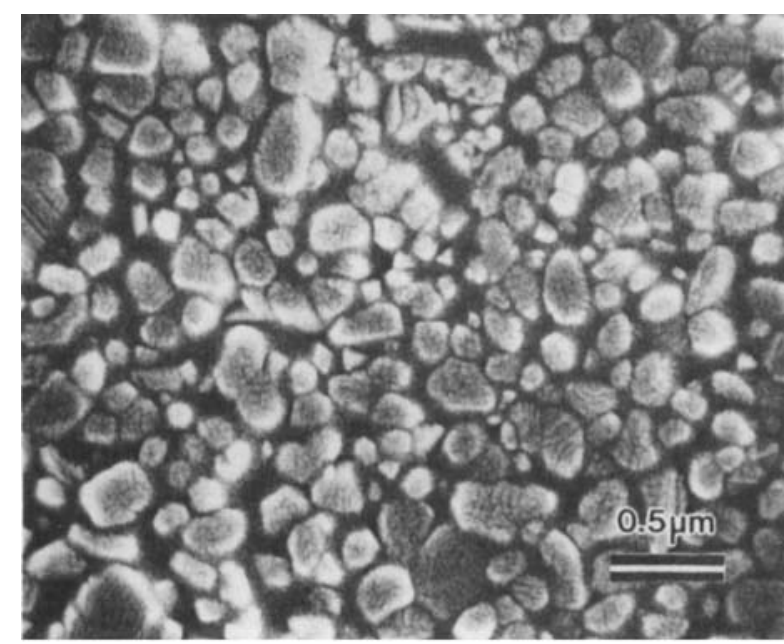

(a)

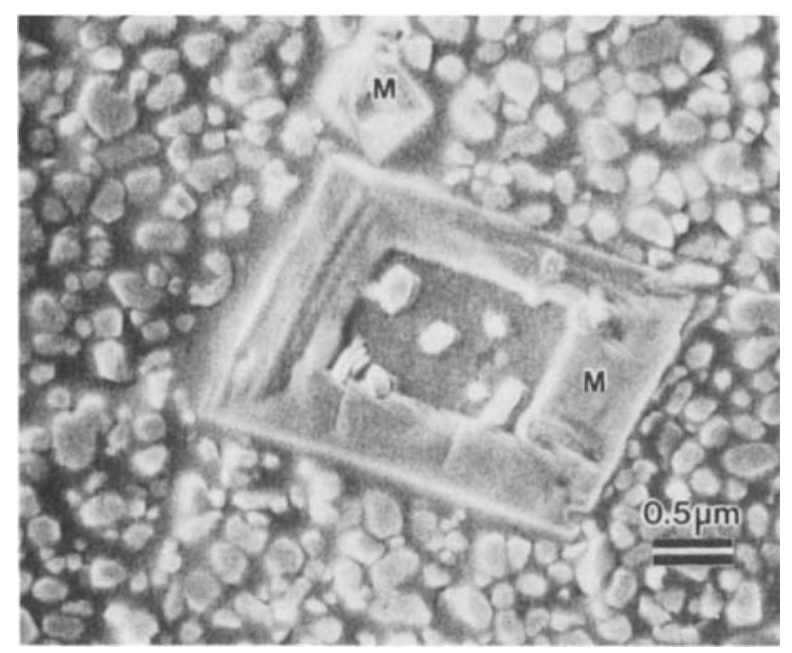

(b)

Fig. 6. SEM micrographs of the premullite after being deformed at (a) $1325^{\circ} \mathrm{C}, 6 \times 10^{-4} / \mathrm{s}, \varepsilon=0.2$; and (b) $1400^{\circ} \mathrm{C}, 2 \times 10^{-2} / \mathrm{s}$, $\varepsilon=0.9$. Two mullite grains are shown in (b).

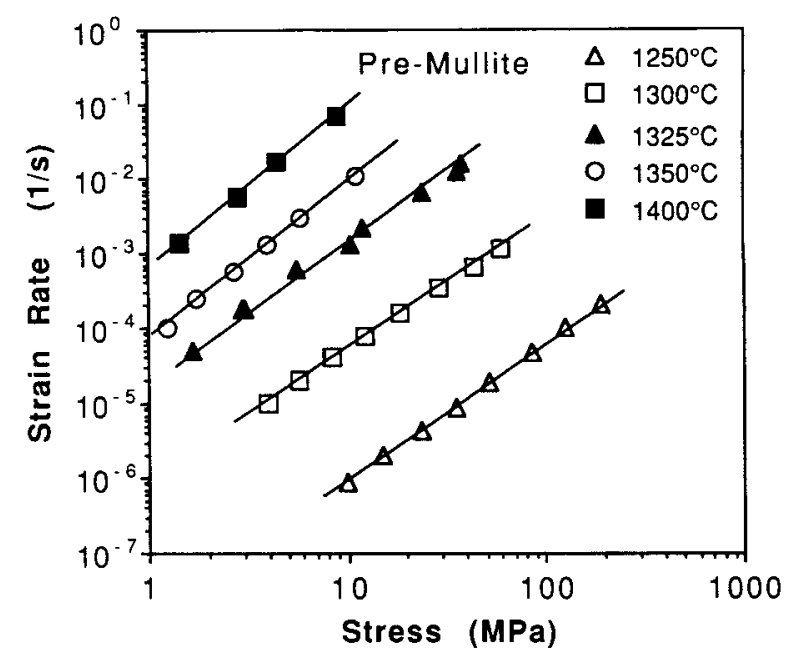

Fig. 7. Relationship between strain rate and stress for premullite at various temperatures.

together with the transition in $n$ at the same temperature range, may be suggestive of a transition in the deformation mechanism. It might be analogous to the transition reported in CuO-added YTZP, from one dominated by glassy-boundaryphase-enhanced diffusion at temperatures below the melting point of the boundary phase to one dominated by liquid-phaseenhanced interface reaction at higher temperatures. ${ }^{20}$

The apparent activation energy values for the deformation of this material are unusually high as compared to either mullite (around $700 \mathrm{~J} / \mathrm{mol}$ ) or other oxide ceramics. The unusually high activation energy may be partially reconciled by recognizing the special nature of the premullite. First, we may assume deformation of this material is primarily controlled by a solution-precipitation process, following similar suggestions by Wang and $\mathrm{Raj}^{21}$ for superplastic deformation of a lithium alumniosilicate $\beta$-spodumene glass ceramic and by Wiederhorn et al. ${ }^{22}$ for creep deformation of a vitreous bonded alumina. If this is the case, then both the heat of solution of the constituent solid phases in the liquid (presumably a lithium aluminosilicate glass) and the activation energy of the viscosity of the glass will enter the temperature dependence of deformation rate. ${ }^{23}$ For the $\beta$-spodumene glass ceramics, the activation energy measured was around $700 \mathrm{~kJ} / \mathrm{mol},{ }^{21}$ whereas that for the vitreous-bonded alumina was around $925 \mathrm{~kJ} / \mathrm{mol}^{22}$ These values are still lower than the one we found.

An additional contribution to the apparent activation energy may come from the microstructural evolution during de-

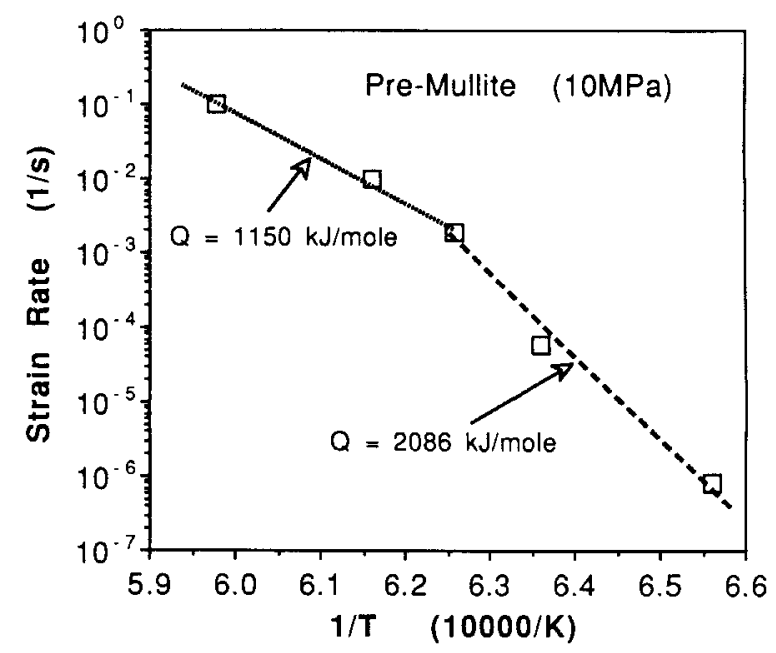

Fig. 8. Temperature dependence of strain rate of premullite at $10 \mathrm{MPa}$. 
formation. We found, with rising temperatures, an increase in glassy phase volume due to the dissolution of alumina. The glassy phase content in volume percent increases from $11 \%$ in the as-sintered material, to $18 \%, 25 \%$, and $30 \%$ when deformed to a strain of 0.15 at increasing temperature of $1250^{\circ}$, $1325^{\circ}$, and $1400^{\circ} \mathrm{C}$, respectively. (The deformation time is shorter at higher temperatures.) Such an observation emphasizes the point that the microstructure is only a transient one and evolves over time during deformation. Higher temperatures not only favor the reaction kinetics but may also command a wider liquid phase region in the phase diagram, which enhances the dissolution process. The resultant increase in the amount of glassy boundary phase tends to enhance deformation and contributes to the apparent activation energy. We also note that the dissolution process acts to compensate for the grain coarsening process as well and results in a slight net decrease in grain size in some cases. Overall, we found that a nearly constant grain size of around $0.26 \mu \mathrm{m}$ was maintained when the samples were deformed below $1450^{\circ} \mathrm{C}$. These unique features of transient phase evolutions are again favorable to superplastic deformation.

\section{(3) Superplastic Forming and Postforming Mullitization}

The superplastic formability of the premullite was demonstrated by punch stretching. A flat disk was stretched by a semispherical punch, with a radius of $6.5 \mathrm{~mm}$, to a semispherical dome shape. When the height of the dome equalled the dome radius, the surface area expanded to approximately twice that of the original. This corresponds to a biaxial engineering strain of $100 \%$.

A typical load-punch displacement curve for punch stretching at $1350^{\circ} \mathrm{C}$, at an average strain rate of $1.2 \times 10^{-3} / \mathrm{s}$, is shown in Fig. 9 for a disk with a thickness of $1.2 \mathrm{~mm}$. The increase in load with the displacement is due to the increase in the deforming area of the specimen. In this case, full stretching to a half-spherical-shaped dome was completed in $10 \mathrm{~min}$.

The as-formed premullite contained a negligible amount of mullite as determined by XRD and SEM microscopy. It was then annealed at $1650^{\circ} \mathrm{C}$ for $8 \mathrm{~h}$ to achieve mullitization. No cracking was found by the latter heat treatment. Indeed, the final mullite work piece $(\sim 1 \mathrm{~mm}$ thick) was translucent. Figure 10 shows photographs of the premullite specimens (A) before stretching and (B) after stretching, as well as the same piece after postforming mullitization (C).

The microstructure of the mullitized sample is shown in Fig. 11. The grain size is large and elongated grains are numerous. No large glassy pockets remained at the scale shown,

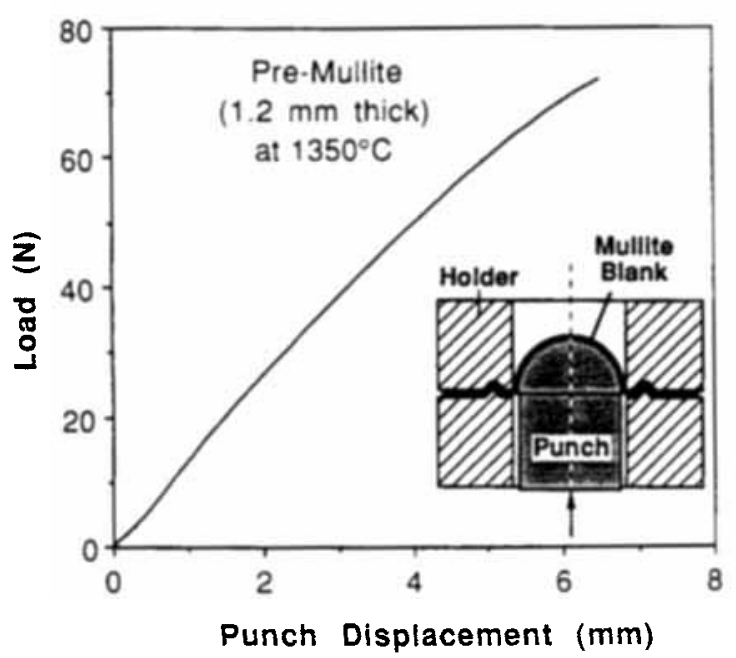

Fig. 9. Forming load versus punch displacement curve for premullite superplastically stretched at $1350^{\circ} \mathrm{C}$. The average strain rate is $1.2 \times 10^{-3} / \mathrm{s}$.

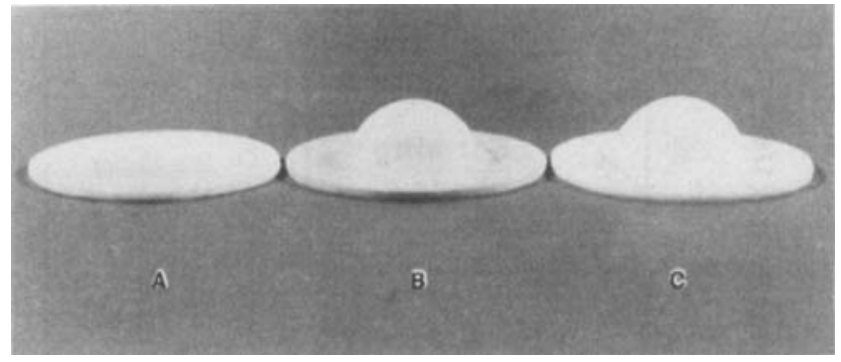

Fig. 10. Premullite (A) before stretching; (B) after stretching; and $(\mathrm{C})$ after complete mullitization

although they certainly exist to some extent, judging from the phase morphology. Except for a trace amount of alumina in some specimens, only mullite reflections were detected by XRD. It might be that the majority of lithia additive either evaporated or was incorporated into the mullite matrix during annealing. The latter possibility seems to be supported by the observation that some exsolution, presumably of lithium-containing substances, appeared on the thermally etched surfaces, which are shown as the white dots in Fig. 11. The analysis of these precipitates by EDAX was not attempted, however, because of the inability of the instrument to detect lithium.

In the process of mullitization, the creep resistance was dramatically improved. The deformation rates of the premullite and fully heat-treated mullite are compared in Fig. 12. A decrease in creep rate by 6 orders of magnitude was found. The latter mullite has a creep resistance comparable to that reported recently by Okamoto et al. ${ }^{\text {" }}$ for a high-purity mullite prepared from a commercial sol-gel grade powder. (The mullite in the present study has a grain size about 4 times that of Okamoto et al.; therefore, if compared at same grain size, the former should creep about an order of magnitude faster than the latter, suggesting the influence of some residual glassy boundary phase as discussed below.)

\section{(4) Mechanical Properties}

The hardness and fracture toughness of the final mullite as measured by Vickers indentation are $11.1 \pm 0.6 \mathrm{GPa}$ and $2.2 \pm 0.4 \mathrm{MPa} \cdot \mathrm{m}^{1 / 2}$, respectively. Both figures are comparable to those reported for mullite ( 7 to $12 \mathrm{GPa}$ and $\sim 2 \mathrm{MPa}$. $\mathrm{m}^{1 / 2}$, respectively)..$^{24,25}$ The strength of the annealed mullite in four-point bending is plotted in Fig. 13 as a function of temperature. The room-temperature fracture strength of $-275 \mathrm{MPa}$ is again comparable to that reported for mullite

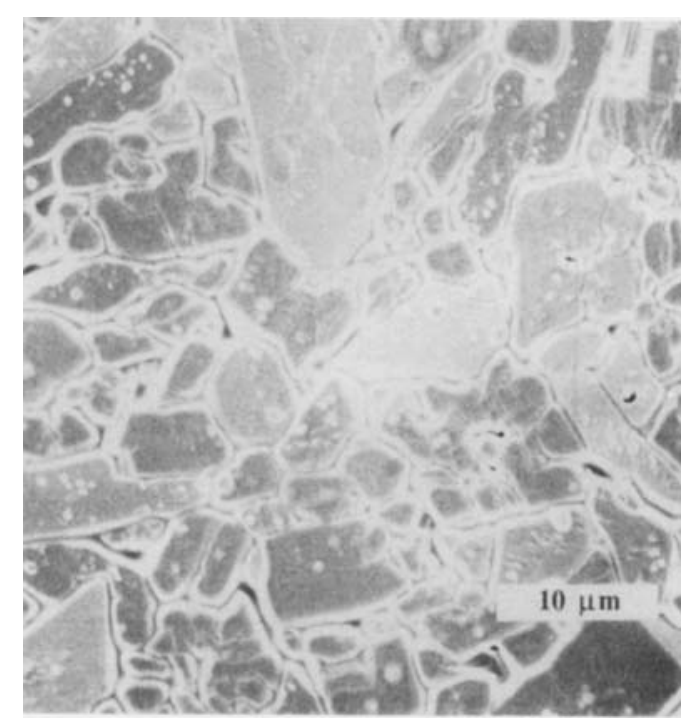

Fig. 11. SEM micrograph of mullite annealed at $1650^{\circ} \mathrm{C}$ for $8 \mathrm{~h}$. 


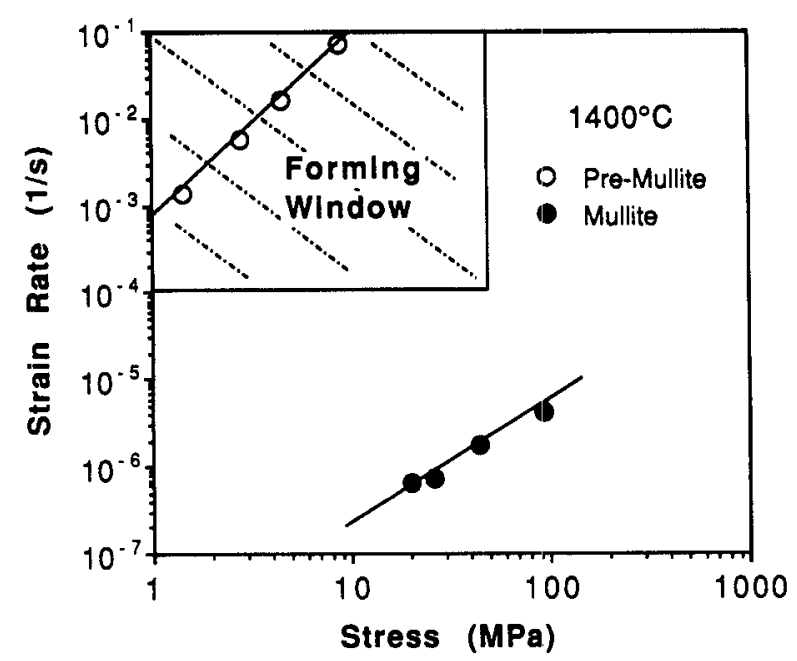

Fig. 12. Strain rate versus stress at $1400^{\circ} \mathrm{C}$ for transient-phaseprocessed mullite specimens before and after annealing, when mullitization lowers the creep rate by 6 orders of magnitude.

( 150 to $400 \mathrm{MPa}){ }^{25-28}$ This level of strength is still maintained at $1200^{\circ} \mathrm{C}$, but it decreases rapidly at temperatures approaching $1400^{\circ} \mathrm{C}$. At the same time, the fracture mode changes from that of brittle fracture to that of semibrittle fracture where specimen failure is preceded by some plastic deformation. Once again, this is indicative of the presence of some residual glassy boundary phase, since glass-free mullite would maintain most of its room-temperature strength up to $\sim 1400^{\circ} \mathrm{C} .{ }^{27-29}$

\section{Summary}

A transient-phase-forming method has been developed for mullite. With the aid of $0.8 \mathrm{wt} \%$ lithia additive, powder compacts of alumina and silica of a mullite stoichiometry can be sintered at $1320^{\circ} \mathrm{C}$ to high density without causing mullitization. This premullite can readily be superplastically shape formed before being subjected to a postforming heat treatment above $1400^{\circ} \mathrm{C}$ which finally converts it to mullite. The presence of a lithia additive which forms a transient lithium aluminosilicate glassy phase is found advantageous in making available the above processing window.

Biaxial stretching of premullite to $100 \%$ strain can be completed at $1350^{\circ} \mathrm{C}$ in $10 \mathrm{~min}$. Deformation characteristics of the superplastic premullite are studied between $1250^{\circ}$ and $1400^{\circ} \mathrm{C}$ with strain rate from $6 \times 10^{-7}$ to $10^{-1} \mathrm{~s}^{-1}$. The deformation rate is extremely sensitive to temperature, having an apparent

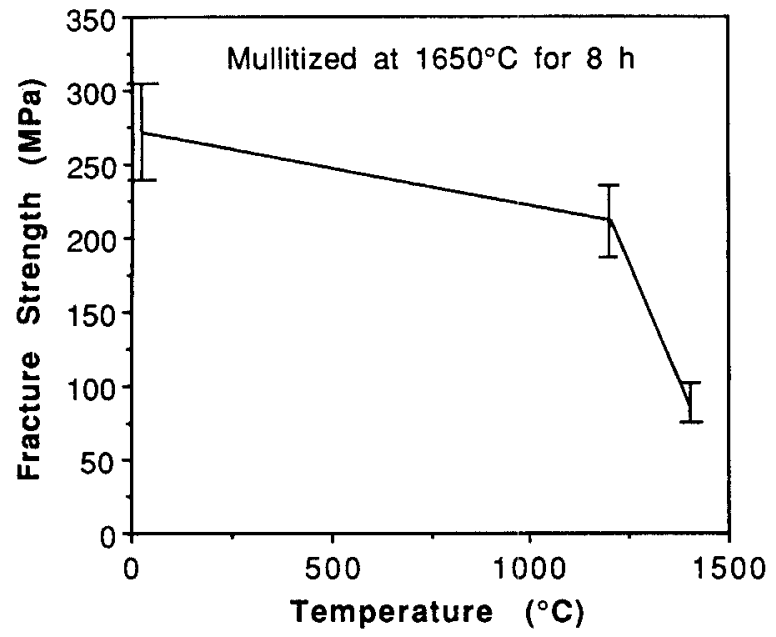

Fig. 13. Fracture strength versus temperature after mullitization. energy in excess of $1200 \mathrm{~kJ} / \mathrm{mol}$. A dramatic improvement in creep resistance (by 6 orders of magnitude), however, can be accomplished by postforming mullitization.

The dissolution of matrix grains into the transient glassy phase during deformation gives rise to an increase in boundary glassy phase content. This dissolution process is accelerated with increasing temperature and may also contribute, in addition to the contributions from viscous flow and melting, to the abnormally high activation energy observed during superplastic deformation. Despite this process, the average grain size remains nearly constant during superplastic deformation.

The final mullite after annealing at $1650^{\circ} \mathrm{C}$ is translucent and has many elongated grains. With an average grain size of $\sim 5 \mu \mathrm{m}$, its creep resistance is comparable to that of some finer-grained high-purity mullite reported in the literature, as are its room-temperature hardness, toughness, and strength. It maintains a fracture strength over $200 \mathrm{MPa}$ at $1200^{\circ} \mathrm{C}$. At $1400^{\circ} \mathrm{C}$ its strength drops to below $100 \mathrm{MPa}$, with its fracture mode changed from brittle to semibrittle because of the existence of a residual glassy phase.

\section{References}

II-W. Chen and L. A. Xue, "Development of Superplastic Structural Ceramics," J. Am. Ceram. Soc., 73 [9] 2585-609 (1990).

${ }^{2} \mathrm{~F}$. Wakai, S. Sakaguchi, and Y. Matsuno, "Superplasticity of Yttria-Stabilized Tetragonal $\mathrm{ZrO}_{2}$ Polycrystals," Adv. Ceram. Mater., 1 [3] 259-63 (1986).

${ }^{3} \mathrm{~L}$. A. Xue, X. Wu, and I-W. Chen, "Superplastic Alumina Ceramics with Grain Growth Inhibitors," J. Am. Ceram. Soc., 74 [4] 842-45 (1991).

${ }^{4} \mathrm{~F}$. Wakai, Y. Kodama, S. Sakaguchi, and T. Nonami, "Superplasticity of Hot Isostatically Pressed Hydroxyapatite," J. Am. Ceram. Soc., 73, 457-60 (1990).

${ }^{5}$ F. Wakai, Y. Kodama, S. Sakaguchi, N. Murayama, K. Izaki, and K. Nihara, "A Superplastic Covalent Crystal Composite," Nature (London), 344, $421-23(1990)$.

b.-G. Wang and R. Raj, "Influence of Hydrostatic Pressure and Humidity on Superplastic Ductility of Two $\beta$-Spodumene Glass-Ceramics," J. Am. Ceram. Soc., $67[6] 385-90$ (1984).

${ }^{7} \mathrm{~F}$. Wakai and H. Kato, "Superplasticity of $\mathrm{TZP} / \mathrm{Al}_{2} \mathrm{O}_{3}$ Composite," $A d v$. Ceram. Mater, 3 [1] 71-76 (1988).

${ }^{8}$ P. A. Lessing, R. S. Gordon, and K. S. Mazdiyasni, "Creep of Polycrystalline Mullite," J. Am. Ceram. Soc., 58 [3-4] 149 (1975).

${ }^{9}$ P. C. Dokko, J. A. Pask, and K. S. Mazdiyasni, "High-Temperature Mechanical Properties of Mullite under Compression," J. Am. Ceram. Soc., 60 [3-4] (1977).

${ }^{10}$ R. A. Penty and D. P. H. Hasselman, "Creep Kinetics of High-Purity, Ultra-Fine Grain Polycrystalline Mullite," Mater. Res. Bull., 7 [10] 1117-24 (1972).

"Y. Okamoto, H. Fukudome, K. Hayashi, and T. Nishikawa, "Creep Deformation of Polycrystalline Mullite," J. Eur. Ceram. Soc. 6, 161-68 (1990).

${ }^{12} \mathrm{C}$. K. Yoon, "Superplastic Flow of Mullite/2Y-TZP Composites"; Ph.D Thesis. Department of Materials Science and Engineering, University of Michigan, Ann Arbor, MI, 1990.

${ }^{13}$ M. Ashizuka, T. Okuno, and Y. Kubota, "Creep of Mullite Ceramics," J. Ceram. Soc. Jpn., 97 [6] 662-68 (1989).

${ }^{14} \mathrm{M}$. Ashizuka, T. Honda, and Y. Kubota, "Effect of Grain Size on Creep in Mullite Ceramics," J. Ceram. Soc. Jpn., 99 [4] 292-95 (1991).

${ }^{15} \mathrm{X}$. Wu and I-W. Chen, "Superplastic Bulging of Fine-Grained Zirconia," J. Am. Ceram. Soc., 73 [3] 746-49 (1990).

${ }^{16} \mathrm{G}$. R. Anstis, P. Chantikul, B. R. Lawn, and D. B. Marshall, "A Critical Evaluation of Indentation Techniques for Measuring Fracture Toughness: I, Direct Crack Measurements," J. Am. Ceram. Soc., 64 [9] 533-38 (1981).

"Powder Diffraction File, Card No. 21-503. Joint Committee on Powder Diffraction Standards, Swarthmore, PA.

${ }^{18}$ Powder Diffraction File, Card No. 35-794. Joint Committee on Powder Diffraction Standards, Swarthmore, PA.

${ }^{19}$ M. D. Sacks, N. Bozkurt, and G.W. Scheiffele, "Fabrication of Mullite and Mullite-Matrix Composites by Transient Viscous Sintering of Composite Powders," J. Am. Ceram. Soc., 74 [10] 2428-37 (1991).

${ }^{20}$ C.-M. J. Hwang and I-W. Chen, "Effect of a Liquid Phase on Superplasticity of 2-mol\%- $\mathrm{Y}_{2} \mathrm{O}_{3}$-Stabilized Tetragonal Zirconia Polycrystals," J. Am Ceram. Soc., 73 [6] 1626-32 (1990).

${ }^{21}$ J.-G. Wang and R. Raj, "Mechanism of Superplastic Flow in a FineGrained Ceramic Containing Some Liquid Phase,"J. Am. Ceram. Soc., 67 [6] 399-409 (1984)

${ }^{22}$ S. M. Wiederhorn, B. J. Hockey, R. F. Krause, Jr., and K. Jakus, "Creep and Fracture of a Vitreous-Bonded Alumina Oxide," J. Mater. Sci., 21, 81024 (1986)

${ }^{23}$ R. Raj and P.E. D. Morgan, "Activation Energies for Densification, Creep, and Grain-Boundary Sliding in Nitrogen Ceramics," J. Am. Ceram. Soc., 64 [10] C-143-C-145 (1981).

${ }^{24} \mathrm{~T}$. Sato, M. Ishizuka, and M. Shimada, "Sintering and Characterization of Mullite-Alumina Composites," Ceram. Intl., 12, 61-65 (1986). 
${ }^{25}$ Coors Ceramic Company, "Material Properties Chart." Structural Division of Coors Ceramics Company, Golden, CO.

${ }^{26} \mathrm{~J}$. M. Rincon, G. Thomas, and J. S. Moya, "Microstructural Study of Sintered Mullite Obtained from Premullite," J. Am. Ceram. Soc., 69 [2] C-29C-31 (1986)

${ }^{27}$ S. Kanzaki, H. Tabata, T. Kumazawa, and S. Obta, "Sintering and Mechanical Properties of Stoichiometric Mullite," J. Am. Ceram. Soc., 68 [1]
C-6-C-7 (1985).

${ }^{28}$ M. G.M. U. Ismail, Z. Nakai, and S. Somiya, "Microstructure and Mechanical Properties of Mullite Prepared by the Sol-Gel Method," J. Am. Ceram. Soc., 70 [1] C-7-C-8 (1987).

${ }^{29}$ I. A. Aksay, D. M. Dabbs, and M. Sarikaya, "Mullite for Structural, Electronic, and Optical Applications," J. Am. Ceram. Soc., 74 [10] 2343-58 (1991). 